\title{
A microplasticity evaluation method in very high cycle fatigue
}

\author{
X. G. Wang, E. S. Feng, C. Jiang*
}

State Key Laboratory of Advanced Design and Manufacturing for Vehicle Body, College of Mechanical and Vehicle Engineering, Hunan University, 410082 Changsha, PR China

\begin{abstract}
:
This paper focuses on the development of a calorimetric method for the microplasticity evaluation in the very high cycle fatigue regime. The proposed method is essentially based on the establishment of an experimental energy balance during the fatigue process. It allows the estimation of the plastic strain of very low magnitude produced by cyclic slip, which is considered as the primary mechanism of the ultrahigh cycle fatigue in the face-centered cubic materials. By the developed method, the plastic strain amplitudes of a polycrystalline copper in the very high cycle fatigue regime are estimated, and its relationship with the fatigue lives is established via the Manson-Coffin law.
\end{abstract}

Keywords: Microplasticity; Very high cycle fatigue; Ultrasonic fatigue; Infrared thermography; Energy dissipation

\footnotetext{
* Corresponding author: C. Jiang
}

Tel.: +86-73188821748; fax: +86-73188822051

Email: jiangc@hnu.edu.cn 


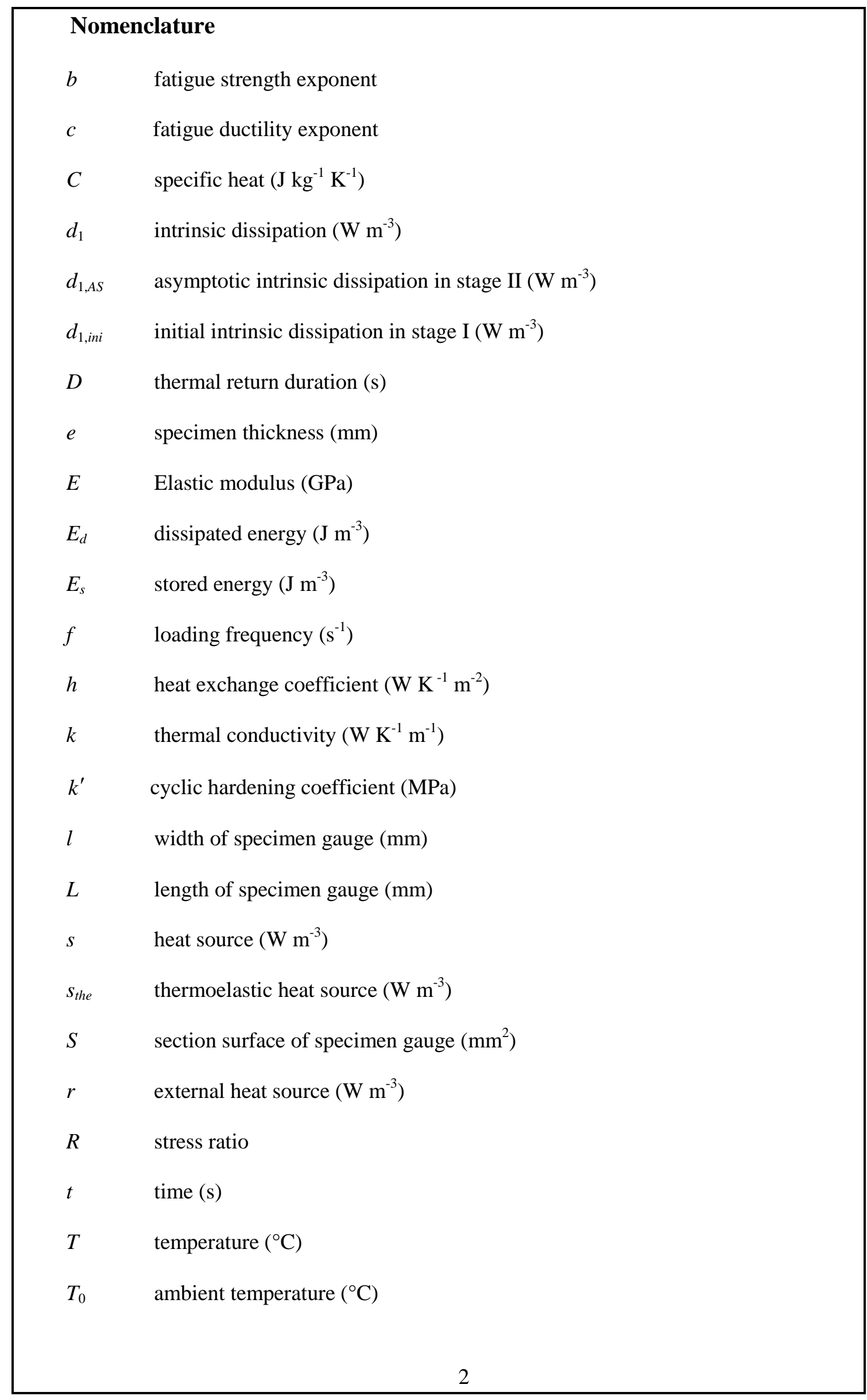




\begin{tabular}{|c|c|}
\hline$T_{1}$ & period of cyclic load (s) \\
\hline$n^{\prime}$ & cyclic hardening exponent \\
\hline$N$ & number of cycles \\
\hline$N_{A S, 0}$ & number of cycles to the start of stage II \\
\hline$N_{A S, f}$ & number of cycles to the end of stage II \\
\hline$\Delta N_{A S}$ & number of cycles of stage II \\
\hline$N_{f}$ & number of cycles to failure \\
\hline$N_{f, p}$ & predicted number of cycles to failure \\
\hline$W_{p}$ & plastic strain energy $\left(\mathrm{J} \mathrm{m}^{-3}\right)$ \\
\hline$\beta$ & fraction of plastic work converted into heat \\
\hline$\varepsilon$ & total strain \\
\hline$\varepsilon_{e}$ & elastic strain \\
\hline$\Delta \varepsilon_{e} / 2$ & elastic strain amplitude \\
\hline$\varepsilon_{f}^{\prime}$ & fatigue ductility coefficient \\
\hline$\varepsilon_{p}$ & plastic strain \\
\hline$\Delta \varepsilon_{p} / 2$ & plastic strain amplitude \\
\hline$\varepsilon_{t h}$ & thermal strain \\
\hline$\theta$ & temperature variation $\left({ }^{\circ} \mathrm{C}\right)$ \\
\hline$\theta_{A S}$ & asymptotic temperature variation $\left({ }^{\circ} \mathrm{C}\right)$ \\
\hline$\rho$ & mass density $\left(\mathrm{kg} \mathrm{m}^{-3}\right)$ \\
\hline$\Delta \sigma / 2$ & stress amplitude $(\mathrm{MPa})$ \\
\hline$\sigma_{f}^{\prime}$ & fatigue strength coefficient (MPa) \\
\hline$\tau$ & time constant characterizing the heat loss ( $\mathrm{s}$ ) \\
\hline
\end{tabular}




\section{Introduction}

Fatigue property is considered as a critical element in the reliability design of engineering structures that may be subjected to cyclic loading under the service conditions [1-4]. For some industry sectors (e.g., aviation, high-speed railway, nuclear industry), it could be in many cases a prime consideration in the safety measures. Now there is an increasing demand on a higher fatigue performance of the materials and components that are expected to be able to resist ultrahigh cycle fatigue. Hence, the study on the very high cycle fatigue (VHCF) has drawn much attention in recent years [5-8]. The development of the ultrasonic fatigue testing allows a typical loading frequency of $20 \mathrm{kHz}$, which makes it possible to perform the VHCF testing in a reasonable time. Substantial VHCF tests show that the fatigue failure may still occur even in a considerably low stress level provided that the number of load cycles is high enough, e.g., $10^{8}$ $10^{11}$ cycles. Thus, it discredits the existence of an endurance limit (or fatigue limit) for most steel alloys as assumed in many textbooks. The original studies on the high strength steels by Japanese researchers [9-11] reveal that the interior inclusion-induced cracking is the main cause of the fatigue failure occurred beyond $10^{7}$ cycles in such materials. A distinct feature of such failures is the formation of the so-called "fish-eye" area originated from a non-metallic inclusion, as the site of the microcrack growth [12-15]. Thus the VHCF mechanism is different from the surface-initiated fatigue that is normally attributed to the effect of persistent slip band (PSB) or surface defect. Hence, the researchers [16-18] propose a duplex expression of the $S-N$ curve to differentiate the VHCF regime from other fatigue regimes according to their different fatigue mechanisms, namely, the eye-fish fracture and surface-initiated fracture.

Nevertheless, the non-metallic inclusion is not the sole cause of the VHCF in metals. For a material that is not possessed of any inclusion, it can still fail after a sufficiently high number of cycles [19-22]. The fatigue failure could be due to irreversible slip accumulation or other reasons. Thus, Mughrabi [16] suggests the classification of the concerned materials into two types: the single phase face-centered cubic (fcc) materials as type I materials in contrast to type 
II materials such as high strength steels. Despite the variety in failure mechanism, a common feature of fatigue damage in metals is the irreversible plastic deformation. A unique characteristic of the plasticity in the VHCF regime is its small magnitude, which makes it difficult to be measured using the routine methods, for instance, by a strain gauge or the recently developed digital image correlation (DIC) method [23]. Most researchers adopted the "indirect" measure on the effect of the irreversible microstructure evolution and microplasticity in the VHCF. The resonant frequency was first used as a dynamic parameter to correlate with the fatigue damage. The studies [24,25] demonstrated that the resonant frequency of the ultrasonic fatigue specimen decreased with crack growth. In a further study, Kumar and his coworkers [26,27] proposed a nonlinearity parameter in the ultrasonic testing to characterize the fatigue damage accumulation. Recently, more fruitful results [28-32] have been achieved using the full-field temperature measurement by infrared thermography (IRT). The IRT has several unique advantages in the fatigue evaluation. First, the temperature variation, as a fatigue indicator, has a sound sensitivity to the microplastic deformation [33-35]. Second, the IRT allows a non-contact full-field measurement on the specimen surface. Thus, the crack site with the most intense thermal dissipation could be readily detected [28-30]. More interestingly, the heat sources associated with the plastic deformation can be estimated from the measured temperature fields via some suitable heat diffusion models [36-39]. In this way, the irreversible fatigue process could be evaluated by the intrinsic dissipation from a viewpoint of thermomechanics.

This paper focuses on an exploration of the IRT-based calorimetric method for the possible microplasticity evaluation in the VHCF regime. The proposed method is essentially based on the establishment of an experimental energy balance in the specimen during the ultrasonic fatigue test. The investigated material is a polycrystalline copper, as the type I material. This paper is organized as follows. First, the material and experimental protocol are introduced. Then, the development of the microplasticity evaluation methodology is elucidated in detail. By the developed method, the plastic strain amplitudes in pure copper under different 
cyclic load levels are estimated, and its relationship with the fatigue lives is studied. Finally, some summary comments are given in the conclusion.

\section{Material and experiments}

The investigated material is a commercially pure copper C11000, according to ASTM designation. It is a kind of electrolytic tough pitch copper with polycrystalline structure. The thermophysical properties of the material are listed in Table 1, which will be used in the thermal analysis. The elastic modulus of the pure copper C11000 was determined in a tensile test, resulting in $E=127 \mathrm{GPa}$.

Table 1 Thermophysical properties of the pure copper $\mathrm{C} 11000$

\begin{tabular}{ccc}
\hline$\rho\left(\mathrm{kg} \mathrm{m}^{-3}\right)$ & $C\left(\mathrm{~J} \mathrm{~kg}^{-1} \mathrm{~K}^{-1}\right)$ & $k\left(\mathrm{~W} \mathrm{~K}^{-1} \mathrm{~m}^{-1}\right)$ \\
\hline 8960 & 400 & 400 \\
\hline
\end{tabular}

The experimental set-up mainly includes an ultrasonic fatigue testing machine (SHIMADZU USF-2000) and an IR imaging system (FLIR SC7700M), as shown in Fig. 1. The fatigue tests were conducted under the symmetric tension-compression condition $(R=-1)$ at a loading frequency $f=20 \mathrm{kHz}$. In order to satisfy the resonance conditions of the ultrasonic fatigue testing, the geometry of the specimen was designed to have the first longitudinal eigen vibration mode at $20 \mathrm{kHz}$. Thus, under the hypothesis of an elastic behavior, the steady-state distribution of the elastic strain along the specimen length direction can be obtained using the elastic wave equation. The corresponding stress can be then calculated by the Hooke's law. Fig. 2(a) shows the geometric dimensions of the specimen with a varying cross section. And an example of the elastic strain amplitude $\Delta \varepsilon_{e} / 2$ and stress amplitude $\Delta \sigma / 2$ distribution along the specimen length under a determined cyclic load $(\Delta \sigma / 2=120 \mathrm{MPa})$ is illustrated in Fig. 2(b). As the present study is aimed at a microplasticity evaluation, the zone of interest (ZOI) is selected as the center of the specimen (a squared region of $2 \times 2 \mathrm{~mm}^{2}$ ) where the stress amplitude is the maximum along the specimen length. 


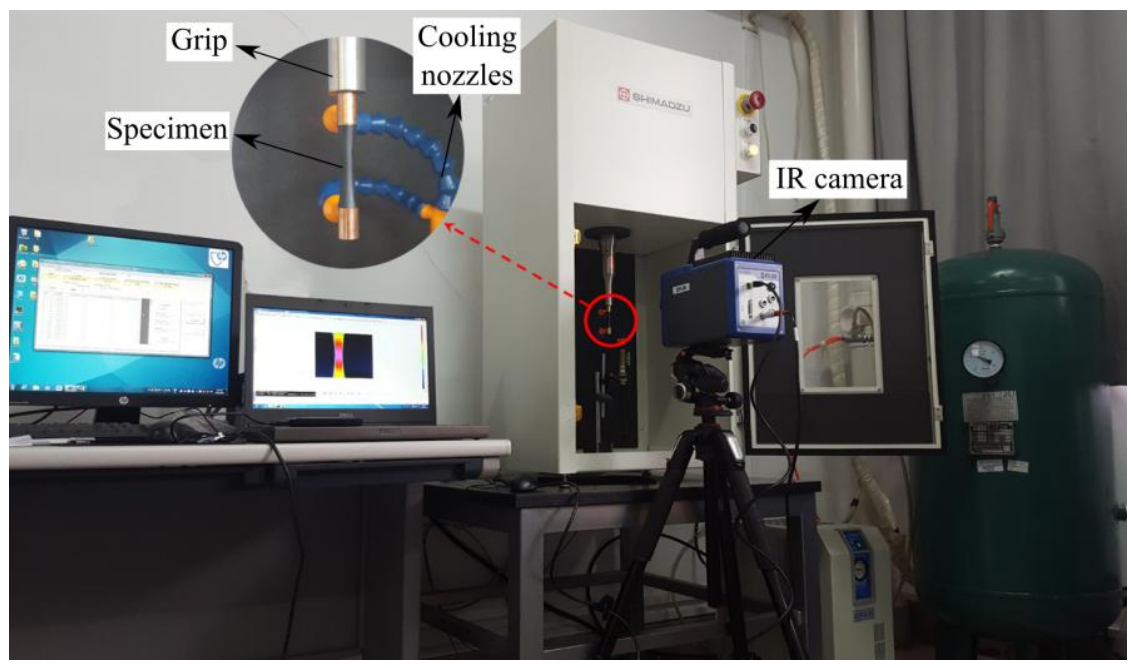

Fig. 1. Experimental set-up of the ultrasonic fatigue testing and thermographic measurement

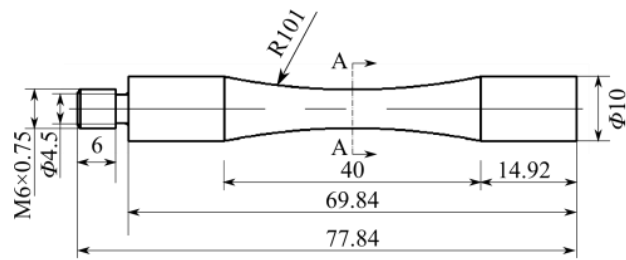

Unit: $\mathrm{mm}$

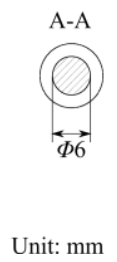

(a)

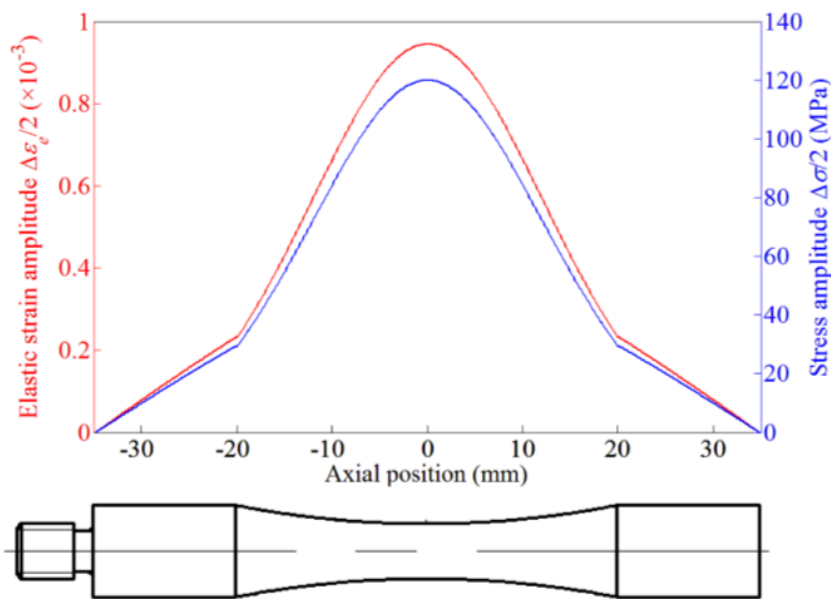

(b)

Fig. 2. (a) Geometric dimensions of the fatigue test specimen, (b) an example of the elastic strain amplitude $\Delta \varepsilon_{e} / 2$ and stress amplitude $\Delta \sigma / 2$ distribution along the specimen length under an imposed stress amplitude $120 \mathrm{MPa}$ in the ZOI

Fourteen constant amplitude fatigue tests were carried out using stress amplitudes in the range between $110 \mathrm{MPa}$ and $150 \mathrm{MPa}$, in order to obtain the $S-N$ curve of the pure polycrystalline copper in the VHCF regime. If failure did not occur within $1 \times 10^{9}$ cycles, the test was suspended. Furthermore, two variable amplitude fatigue tests serving for the microplastic strain assessment were performed by following a stepwise loading procedure, as schematically shown in Fig. 3. For a single specimen, the imposed stress amplitude is enhanced block by block starting from $91 \mathrm{MPa}$ to $169 \mathrm{MPa}$ with an interval of $3 \mathrm{MPa}$, and 
each loading block contains a number of cycles from $4 \times 10^{4}$ to $1 \times 10^{5}$. By the proposed calorimetric method, the plastic strain amplitude under the stress level in each block can be estimated. Here it is also worthy to note that during the fatigue test the specimen is cooled uninterruptedly by the compressed air in order to avoid the overheating of the material under the high loading frequency.

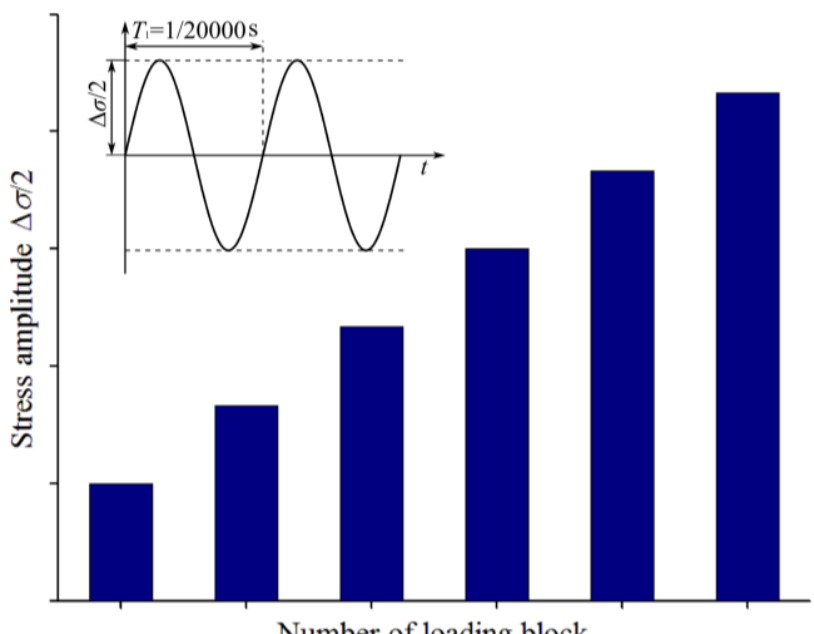

Fig. 3. Schematic presentation of the stepwise loading procedure in the variable amplitude fatigue test

The thermographic measurement was conducted using an IR focal-plane-array camera at room temperature. The IR camera is equipped with an MCT $640 \times 512$ elements detector that has a spectral response $3.7-4.8 \mu \mathrm{m}$ in wavelength. Its thermal sensitivity, evaluated by the noise equivalent temperature difference (NETD), is typically less than $20 \mathrm{mK}$ at room temperature. A pixel-to-pixel calibration [40] was carried out on the IR camera by using an extended black body to ensure the temperature measurement precision. And the inevitable radiometric artifacts were eliminated or decreased by performing the non-uniformity correction (NUC). Moreover, the surfaces of the fatigue specimens were deposited by the matt black coating to have a high and uniform emissivity. And some thermal insulation measures were employed for the purpose of optimizing the IR measurement conditions.

\section{Methodology}

\subsection{Intrinsic dissipation evaluation}


In the VHCF regime, several deformation mechanisms may coexist in the fcc materials. They are elasticity, plasticity, and thermal expansion. Then the total strain $\varepsilon$ can be divided into three parts: elastic strain $\varepsilon_{e}$, plastic strain $\varepsilon_{p}$, and thermal strain $\varepsilon_{t h}$

$$
\varepsilon=\varepsilon_{e}+\varepsilon_{p}+\varepsilon_{t h}
$$

The elastic strain $\varepsilon_{e}$ is reversible, which can be related to the temperature variation due to the thermoelastic effect [41]. In a periodic fatigue load, the thermoelasticity will lead to a periodic variation of temperature that decreases with a positive $\varepsilon_{e}$ and increases with a negative $\varepsilon_{e}$ in a linear relationship. Thus, the elastic strain pertains to a thermoelastic heat source $s_{t h e}$. The plastic strain $\varepsilon_{p}$ is a type of irreversible strain. It is related to the permanent fatigue damage, contributing to an irreversible intrinsic dissipation, denoted by $d_{1}$. The thermal strain $\varepsilon_{t h}$ is produced by the thermal expansion of the material during the self-heating fatigue process. Its influence on the temperature variation is characterized by the thermomechanical coupling effect. This effect is usually rather slight and can be neglected for the fatigue test conducted at room temperature [32,37-39]. Finally, taking into account of the possible external heat source $r$ during the fatigue test, the total heat source $s$ can be estimated by

$$
s=s_{\text {the }}+d_{1}+r
$$

Based on the first law of thermodynamics, Chrysochoos and his collaborators [43-46] proposed the specific form of heat diffusion equation to determine the heat sources from the measured temperature fields of specimen surface in the fatigue test. It is formulated as below

$$
\rho C \frac{\partial \theta}{\partial t}-k \Delta \theta=s_{\text {the }}+d_{1}+r
$$

where $\rho$ stands for the mass density, $C$ the specific heat, $\theta\left(=T-T_{0}\right)$ the temperature variation, $t$ the current time, $k$ the isotropic thermal conductivity, and $\Delta$ the Laplace operator.

Concerning the ultrasonic fatigue test in the present study, the stress ratio $R$ is set to be -1 . In this case, the heat source $s_{\text {the }}$ in a load cycle returns to null due to thermoelasticity. Thus, the thermoelastic term can be neglected in the heat source estimation.

The external heat source $r$ characterizes the heat exchange between the specimen and the surroundings. In the self-heating fatigue test performed at room temperature, it represents 
actually the heat loss into the environment. Here the heat loss may be operated in two basic ways. The first way is the heat diffusion into the grip by conduction, and the second way is the heat loss into the air by convection. In the present ultrasonic fatigue test, a forced convection by compressed air cooling was employed at the specimen ends in order to restrict the selfheating effect of the material. Thus, the heat loss may be significant owing to the strong thermal convection condition. Nevertheless, to precisely evaluate the heat loss is a challenging issue as it is strongly dependent on the boundary conditions and environmental factors. Generally, a simple solution can be adopted by presuming a linear relationship between the heat loss and temperature variation:

$$
r=-\rho C \frac{\theta}{\tau}
$$

where $\tau$ represents a time constant characterizing the heat loss.

According to the above estimations on $s_{\text {the }}$ and $r$, Eq. (3) can be rewritten by

$$
\rho C\left(\frac{\partial \theta}{\partial t}+\frac{\theta}{\tau}\right)-k \Delta \theta=d_{1}
$$

The current issue is the numerical solution of the intrinsic dissipation $d_{1}$ from the above equation. In the literature [32,36-39], a variety of heat diffusion models from $0 \mathrm{D}, 1 \mathrm{D}$ to $2 \mathrm{D}$ have been proposed. Concerning the VHCF test, the 1D model for describing the heat diffusion problem in the specimen is considered more appropriate than the $2 \mathrm{D}$ or $0 \mathrm{D}$ model. Because on the one hand, the $1 \mathrm{D}$ heat diffusion model is not that sensitive to the thermal noise as the $2 \mathrm{D}$ model. Be aware that the fatigue test is normally possessed of a poor thermal signal-to-noise ratio [37]. On the other hand, the $1 \mathrm{D}$ model allows the computation of intrinsic dissipation distribution along the loading axis. It provides, therefore, more information than the $0 \mathrm{D}$ model that gives only the global intrinsic dissipation. Hence, a 1D heat diffusion model developed in $[32,39]$ is adopted in the present study. It is dedicated to the fatigue specimen with a varying cross section $S(x)$, formulated as below

$$
\rho C\left(\frac{\partial \overline{\bar{\theta}}}{\partial t}+\frac{\overline{\bar{\theta}}}{\tau^{1 D}}\right)-k\left(\frac{\partial^{2} \overline{\bar{\theta}}}{\partial x^{2}}+\frac{1}{S} \frac{d S}{d x} \frac{\partial \overline{\bar{\theta}}}{\partial x}\right)=\overline{\bar{d}}_{1}
$$


where $\overline{\bar{\theta}}$ and $\overline{\bar{d}}_{1}$ represent the average temperature variation and intrinsic dissipation over the cross section, respectively. $\tau^{I D}$ refers to the time constant $\tau$ in 1D model characterizing the global lateral heat exchange with the environment. It can be estimated by

$$
\tau^{1 D}(x)=\frac{\rho C S(x)}{2 h(e+l(x))}=\frac{\rho \operatorname{Cel}(x)}{2 h(e+l(x))}
$$

where $h$ represents the heat exchange coefficient, $e$ the specimen thickness, and $l(x)$ the varying width of specimen gauge.

The time constant $\tau^{l D}$ depends on the material constants $\rho$ and $C$, specimen geometry, and the heat exchange coefficient $h$. From an experimental standpoint, it can usually be estimated through a thermal return to equilibrium by removing the load in the fatigue test [32]. In this case, the intrinsic dissipation $d_{1}$ equals to zero since there is no more mechanical energy input. In Eq. (7) the only unknown parameter for evaluating $\tau^{l D}$ is the heat exchange coefficient $h$. It can be estimated using the method of least squares by minimizing the following function $R(h)$ :

$$
R(h)=\iint_{L \times D}\left[\rho C\left(\frac{\partial \overline{\bar{\theta}}}{\partial t}+\frac{\overline{\bar{\theta}}}{\tau^{1 D}(h)}\right)-k\left(\frac{\partial^{2} \overline{\bar{\theta}}}{\partial x^{2}}+\frac{1}{S} \frac{d S}{d x} \frac{\partial \overline{\bar{\theta}}}{\partial x}\right)\right]^{2} d x d t
$$

where $L$ stands for the gauge length, and $D$ the thermal return duration.

The optimal value of $h$, denoted by $h_{\text {opt }}$, is expected to satisfy

$$
\left.\frac{\partial R(h)}{\partial h}\right|_{h=h_{o p t}}=0
$$

The parameter $h$ can be solved from the above differential equation, and then the time constant $\tau^{l D}$ is accessible by Eq. (7). Thus, the intrinsic dissipation in $1 \mathrm{D}$ along the specimen length direction can be evaluated according to Eq. (6).

\subsection{Plastic strain assessment}

Fatigue analyses are conducted generally based on the so-called stabilized cycle, on which stress amplitude, strain amplitude, and plastic strain energy are determined after the initial shakedown stage of the first load cycles. From the thermomechanical viewpoint, the stabilized cycle corresponds to a thermal equilibrium stage. The temperature or intrinsic dissipation at 
this stage is considered representative and can, therefore, be used for the fatigue evaluation [42-44].

Extensive studies [28-34,42-44] have demonstrated that three stages of temperature evolution can be observed under the cyclic load when the applied stress amplitude is above a certain level. It can be schematically illustrated by a diagram of temperature variation $\theta$ versus the number of cycles $N$, as shown in Fig. 4. In the initial stage I, the temperature of specimen surface increases quickly until an equilibrium state is reached between the heat production and thermal exchange with the surroundings. It leads to a stabilized stage II characterized by an asymptotic temperature variation $\theta_{A S}$ from $N_{A S, 0}$ to $N_{A S, f}$, which is predominant in the lifespan of the specimen. Then in the final stage III before fatigue failure, the equilibrium state is terminated, and a rapid temperature growth takes place as the consequence of macrocrack propagation. This three-stage evolution trend of temperature applies not only to the high cycle fatigue (HCF) regime [44] but also to the VHCF regime [28-30] provided that the applied stress amplitude is within an appropriate range.

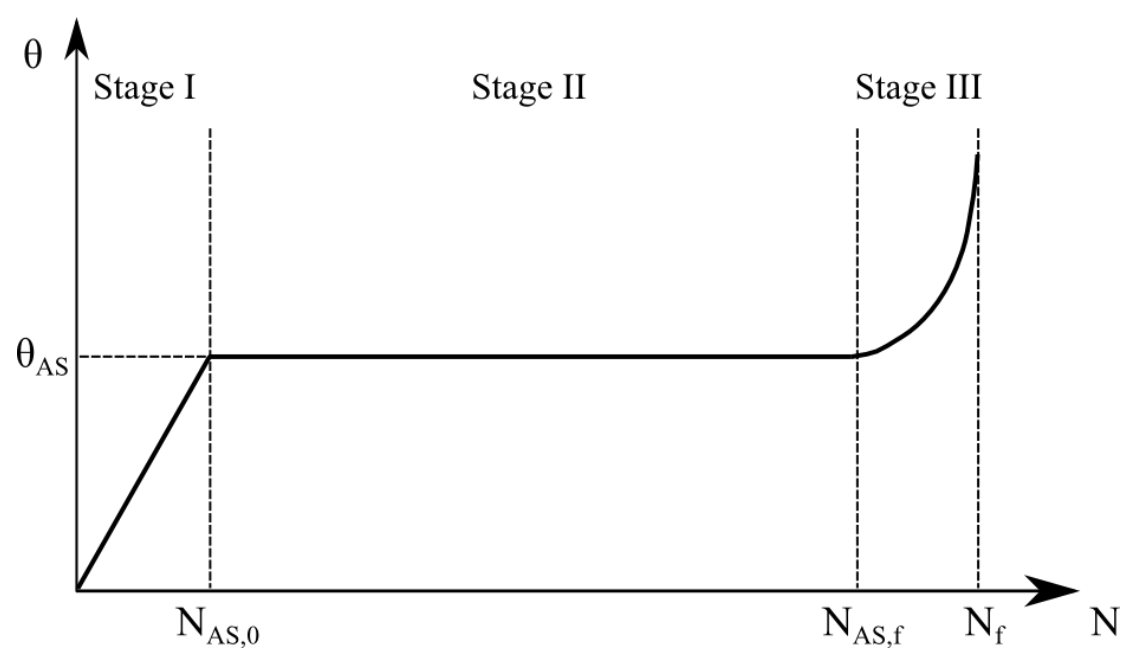

Fig. 4. Schematic illustration of the three temperature evolution stages I, II, and III in the fatigue test

Focusing on the thermal equilibrium stage II, the temperature variation rate $\frac{\partial \theta}{\partial t}$ equals to zero in this stage. Thus, an asymptotic (or stabilized) intrinsic dissipation $d_{1, A S}$ can be introduced. Its one-dimensional form $\overline{\bar{d}}_{1, A S}$ is accessible through Eq. (6): 


$$
\rho C \frac{\overline{\bar{\theta}}_{A S}}{\tau^{1 D}}-k\left(\frac{\partial^{2} \overline{\bar{\theta}}_{A S}}{\partial x^{2}}+\frac{1}{S} \frac{d S}{d x} \frac{\partial \overline{\bar{\theta}}_{A S}}{\partial x}\right)=\overline{\bar{d}}_{1, A S}
$$

The objective of this analysis is the estimation of plastic strain in stage II. To this end, an energy balance is necessary to be established between the plastic work and dissipated energy. As is well known, the heat dissipation takes a significant portion of the plastic work but not the entire. Accompanied with the heat dissipation, a part of the mechanical energy will be stored within the material participating in the microstructure evolution, so-called the stored energy $E_{s}$ (or latent energy) [45]. Here a factor $\beta$ is conventionally used to represent the fraction of plastic work $W_{p}$ converted into dissipated energy $E_{d}$ :

$$
\beta=\frac{E_{d}}{W_{p}}=\frac{W_{p}-E_{s}}{W_{p}}
$$

The above equation can be expressed in the form of an energy balance between the plastic work and dissipated energy:

$$
E_{d}=\beta W_{p}
$$

In the VHCF regime, the elasticity predominates over the plasticity. In most cases, it leads to a quasi-linear stress-strain hysteresis loop. Nevertheless, the plastic strain is small but not negligible. The energy dissipation is a solid evidence of the plastic work [28-34]. In this circumstance, the hysteresis loop can be reasonably simplified as an elliptical form [46]. The stress amplitude $\Delta \sigma / 2$ is taken as the length of the semi-major axis and the plastic strain amplitude $\Delta \varepsilon_{p} / 2$ that of the semi-minor axis. Then the plastic work in a load cycle can be estimated by

$$
W_{P}=\pi \frac{\Delta \sigma}{2} \frac{\Delta \varepsilon_{p}}{2}
$$

Based on the estimated heat sources, the dissipated energy per cycle in stage II can be obtained through the integration of the intrinsic dissipation $\overline{\bar{d}}_{1, A S}$ :

$$
E_{d}=\int_{t}^{t+T_{1}} \overline{\bar{d}}_{1, A S} d t
$$

where $T_{1}(=1 / f)$ represents the period of the cyclic load. 
Eqs. (13) and (14) can be correlated through the energy balance stated in Eq. (12), then the plastic strain amplitude $\Delta \varepsilon_{p} / 2$ can be obtained through

$$
\frac{\Delta \varepsilon_{p}}{2}=\frac{\int_{t}^{t+T_{1}} \overline{\bar{d}}_{1, A S} d t}{\beta \pi \frac{\Delta \sigma}{2}}
$$

Here the factor $\beta$ is generally considered as a material constant. Concerning the studied material polycrystalline copper in this work, its value of $\beta$ is about 0.9 according to the calorimetric experiments conducted by Farren and Taylor [45]. The above equation enables the estimation of the plastic strain amplitude $\Delta \varepsilon_{p} / 2$ for a given stress amplitude $\Delta \sigma / 2$ based on the heat source assessment in the thermal equilibrium stage.

An alternative approach for the plasticity evaluation is to utilize the initial fatigue stage with rapid temperature increase, i.e., the stage I in Fig. 4, as employed in Ref [47]. A specialty of the ultrasonic fatigue test is the high loading frequency, which is typically three orders of magnitude higher than that used in the traditional hydraulic fatigue test system. In this circumstance, an adiabatic condition is reasonable to be assumed in the initial temperature increase stage before a thermal equilibrium state is reached. In other words, it is supposed that there is no heat loss during stage I. In this case, the time constant $\tau$ tends to be infinite, and the external heat source $r(=-\rho C \theta / \tau)$ can be neglected. Thus, the initial intrinsic dissipation in stage I, denoted by $d_{1, \text { ini }}$, can be estimated according to Eq. (6). Its 1D form $\overline{\bar{d}}_{1, \text { ini }}$ is expressed as below

$$
\rho C \frac{\partial \overline{\bar{\theta}}}{\partial t}-k\left(\frac{\partial^{2} \overline{\bar{\theta}}}{\partial x^{2}}+\frac{1}{S} \frac{d S}{d x} \frac{\partial \overline{\bar{\theta}}}{\partial x}\right)=\overline{\bar{d}}_{1, i n i}
$$

Numerous studies [28-34] have shown that the temperature increase in stage $I$ is approximately linear. Then the temperature variation rate $\frac{\partial \overline{\bar{\theta}}}{\partial t}$ is quasi-constant. Thus the estimated $\overline{\bar{d}}_{1, \text { ini }}$ is supposed to be a fixed value (i.e., time-independent) during stage I. Here the evaluation of the plastic strain amplitude follows the same path with the first approach. The dissipated energy in stage I is accessible through 


$$
E_{d}=\int_{t}^{t+T_{1}} \overline{\bar{d}}_{1, i n i} d t
$$

Then the plastic strain amplitude can be obtained by

$$
\frac{\Delta \varepsilon_{p}}{2}=\frac{\int_{t}^{t+T_{1}} \overline{\bar{d}}_{1, i n i} d t}{\beta \pi \frac{\Delta \sigma}{2}}
$$

Now two approaches are available for the microplasticity evaluation in the VHCF test. In principle, the first approach is preferred over the second one as it is based on the stabilized cycle analysis in which the hysteresis loop is normally unvarying. For certain metallic materials, the hysteresis loop may be unstable during the first load cycles due to plastic adaptation or other effects. Nevertheless, for the cases that a thermal equilibrium state cannot be reached under relatively high stress amplitudes due to, for instance, ratcheting effect (with a net plastic strain accumulation during each cycle), the second approach can be used instead of the first approach for the plasticity evaluation.

To the best of our knowledge, the original idea of utilizing the initial temperature increase for the microplastic strain assessment (i.e., the second approach in the present work) in the VHCF is proposed by Zettl et al. in [47]. Its principle based on an experimental energy balance analysis inspired the present authors to develop the advanced new methods. Indeed, some distinct improvements have been achieved in this work. First, the full-field infrared thermography is employed instead of the thermocouple so that the plastic strain distribution can be possibly evaluated. Second, the heat sources are estimated from the temperature fields by considering the thermal conduction and convection conditions in an appropriate manner. Third, a more comprehensive energy balance analysis is conducted by taking into account the existence of the stored energy. Fourth, the stabilized stage based analysis (i.e., the first approach) has been developed that is considered preferable for the plastic strain assessment in the fatigue test.

The following section concerns the results and discussion of the application of the proposed method to the VHCF tests. 


\section{Results and discussion}

\subsection{Experimental assessment of plastic strain amplitude}

The three-stage evolution trend of temperature is generally observed in the constant amplitude fatigue tests performed under the stress amplitudes from $110 \mathrm{MPa}$ to $150 \mathrm{MPa}$. For the relatively lower stress amplitudes, the temperature in stage II shows an asymptotic stability with limited variations. Nonetheless, for the relatively higher stress amplitudes, a gradual temperature increase could be observed in stage II, though it shows a distinct stabilized feature on the whole comparing to the other two stages. For the former case, the first approach based on the stabilized intrinsic dissipation $\overline{\bar{d}}_{1, A S}$ can be used for the plastic strain estimation by Eq. (15). And for the latter case, the second approach based on the initial intrinsic dissipation $\overline{\bar{d}}_{1, i n i}$ can be adopted via Eq. (18). Fig. 5 illustrates an example of the temperature evolution of specimen surface under the stress amplitude $130 \mathrm{MPa}$. The three stages of temperature evolution can be noted in the figure. Here it should be emphasized that the temperature variation in stage II may also be influenced by the change of some environmental factors considering that a VHCF test at $20 \mathrm{kHz}$ for $10^{9}$ cycles will take about 14 hours. If one focuses on only the forepart of stage II, an asymptotic temperature variation is normally reachable.

In Fig. 5, some selected temperature fields at the different heat development stages are also exhibited. It can be remarked that the ZOI in the specimen center is invariably the hottest zone on the specimen surface during the fatigue test. Thus, it is corresponding to the region with the most intense plastic deformation and therefore the critical site of fatigue damage. Then the microplasticity evaluation is focused on the ZOI of the specimen in this analysis. 


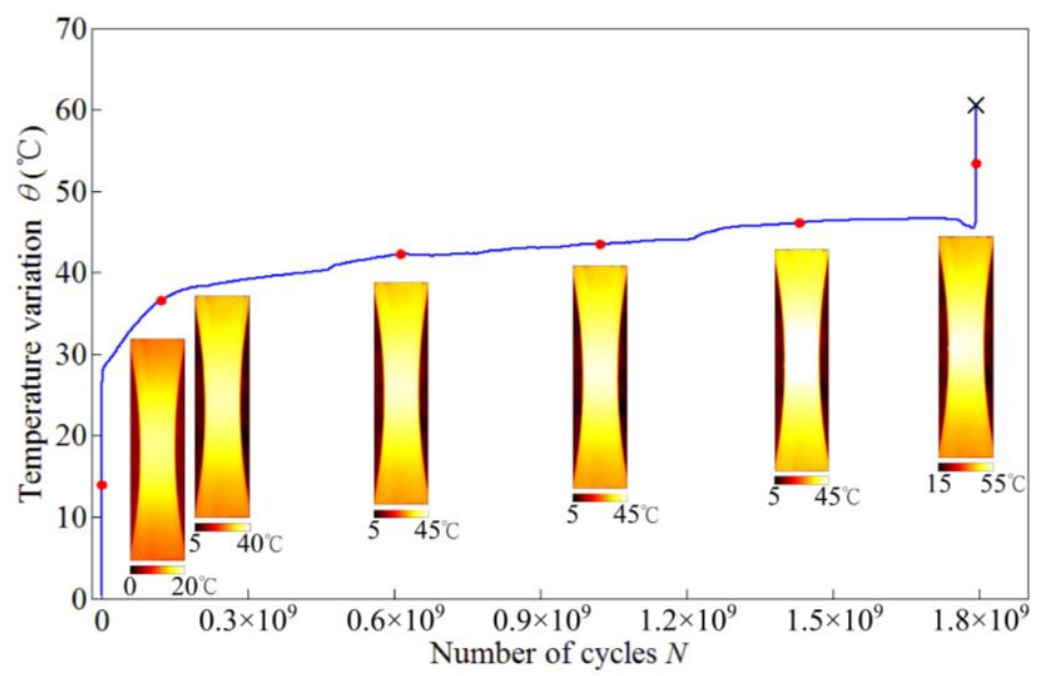

Fig. 5. The temperature evolution of specimen surface under the stress amplitude $130 \mathrm{MPa}$

The calculation of the plastic strain amplitude follows such a procedure. First, the temperature variation on the specimen surface under fatigue load is available from the thermographic measurement. Then the intrinsic dissipation can be estimated from the measured temperature fields by considering the heat diffusion conditions through Eq. (10) or (16). Thus, the plastic strain amplitude can be obtained via Eq. (15) or (18). An example of the calculation is shown in Fig. 6, which corresponds to the fatigue test under the stress amplitude $120 \mathrm{MPa}$. First, Fig. 6(a) shows the profile of the elastic strain amplitude along the loading axis of the specimen obtained using the elastic wave equation. Then the profiles of the temperature variation and estimated intrinsic dissipation are illustrated in Fig. 6(b) and (c), respectively. Finally, Fig. 6(d) exhibits the profile of the plastic strain amplitude along the loading direction. It can be noted in Fig. 6(d) that the plastic strain shows more concentrated in the specimen center than the elastic strain, where the decrease of strain value is sharp from the ZOI to the two sides of the specimen. It verifies again that the selected ZOI is possessed of the maximum plastic strain on the specimen surface. Hence, the average plastic strain amplitude in the ZOI is reasonable to be adopted as the damage factor for the fatigue characterization of the pure polycrystalline copper. 


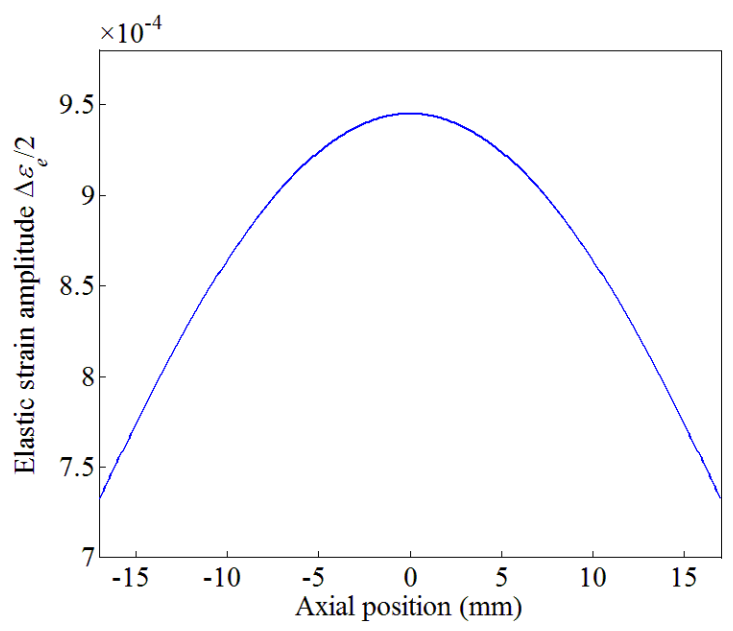

(a)

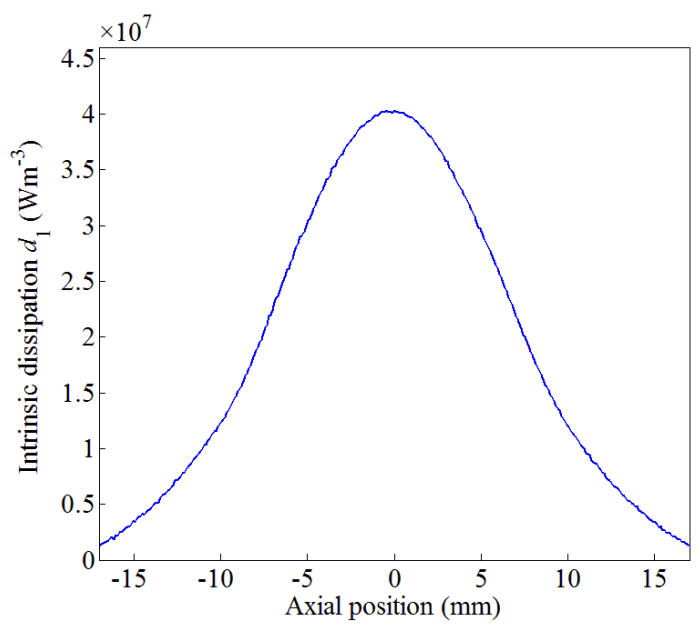

(c)

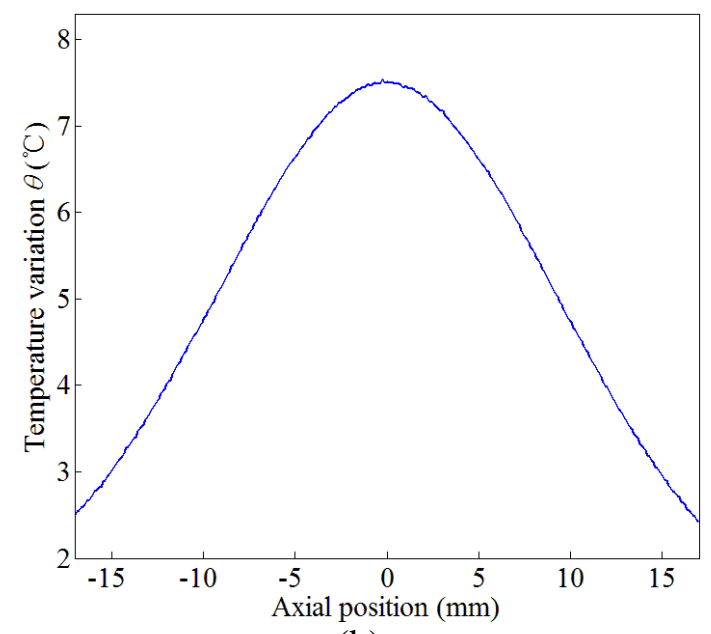

(b)

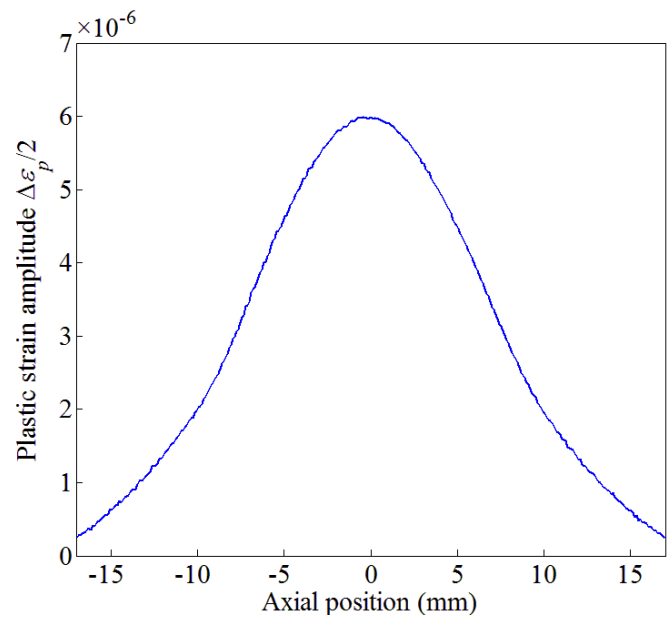

(d)

Fig. 6. The profiles of the different physical quantities along the loading axis of the specimen under the stress amplitude $120 \mathrm{MPa}$ : (a) elastic strain amplitude $\Delta \varepsilon_{e} / 2$, (b) temperature variation $\theta$, (c) intrinsic dissipation $d_{1}$, and (d) plastic strain amplitude $\Delta \varepsilon_{p} / 2$

\subsection{Relationship between plastic strain amplitude and stress amplitude}

The plastic strain amplitude under each stress amplitude in the fatigue tests was calculated, and the obtained data $\Delta \varepsilon_{p} / 2-\Delta \sigma / 2$ are plotted in Fig. 7. It shows that the plastic strain amplitude develops rather slowly within the low stress amplitude range from $91 \mathrm{MPa}$ to about $140 \mathrm{MPa}$. Then a turning point appears, and the plastic strain amplitude exhibits a very rapid growth at increasing stress amplitudes. For instance, the magnitude of $\Delta \varepsilon_{p} / 2$ under the maximum applied $\Delta \sigma / 2=169 \mathrm{MPa}$ is about $4.38 \times 10^{-4}$, which is 32 times as high as that under $\Delta \sigma / 2=138 \mathrm{MPa}$ 
$\left(\Delta \varepsilon_{p} / 2=1.37 \times 10^{-5}\right)$ and 94 times as high as that under $\Delta \sigma / 2=91 \mathrm{MPa}\left(\Delta \varepsilon_{p} / 2=4.64 \times 10^{-6}\right) . \mathrm{In}$ general, the microplasticity with the plastic strain amplitude on the order of magnitude of $10^{-6}$ (i.e., the level of microstrain) is observed below the stress amplitude $130 \mathrm{MPa}$, which corresponds to a fatigue life on the order of $10^{7}$ cycles. As the VHCF regime beyond $10^{7}$ cycles is the focus of the present study, it is intriguing to attempt to establish a relationship between the estimated plastic strain amplitudes and the stress amplitudes below $130 \mathrm{MPa}$. And their relationship is supposed to satisfy a power function as follow

$$
\frac{\Delta \sigma}{2}=k^{\prime}\left(\frac{\Delta \varepsilon_{p}}{2}\right)^{n^{\prime}}
$$

where $k^{\prime}$ represents the cyclic hardening coefficient and $n^{\prime}$ the cyclic hardening exponent.

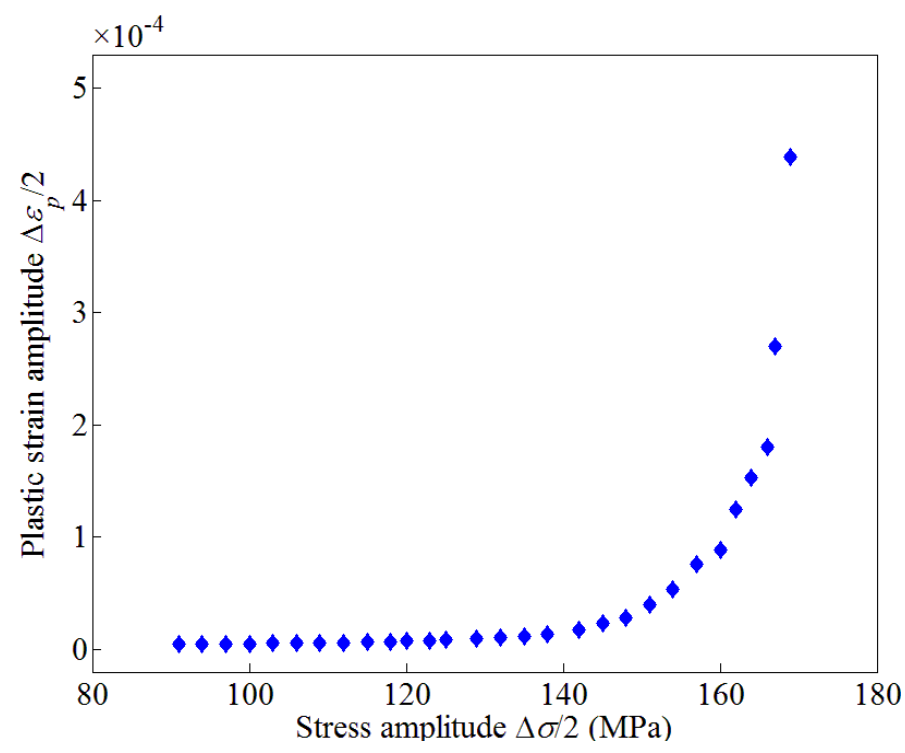

Fig. 7. The plastic strain amplitude $\Delta \varepsilon_{p} / 2$ versus stress amplitude $\Delta \sigma / 2$ in the range from 91

$$
\text { MPa to } 169 \mathrm{MPa}
$$

The cyclic hardening parameters were determined by fitting the data using the method of least squares, leading to $k^{\prime}=3.31 \times 10^{4} \mathrm{MPa}$ and $n^{\prime}=0.48$. The $\Delta \sigma / 2-\Delta \varepsilon_{p} / 2$ regression relationship via Eq. (19) is plotted in a double-logarithm coordinate, as shown in Fig. 8. A satisfactory linearity between the $\lg (\Delta \sigma / 2)$ and $\lg \left(\Delta \varepsilon_{p} / 2\right)$ can be remarked. Indeed, Eq. (19) states a cyclic stress-strain relation of the investigated pure copper in the VHCF regime. In principle, the proposed calorimetric method enables such relationship to be built on any kind of 
metallic material. It may therefore provide a potential value in study of the cyclic plastic deformation response of materials, especially for the micro strain cases.

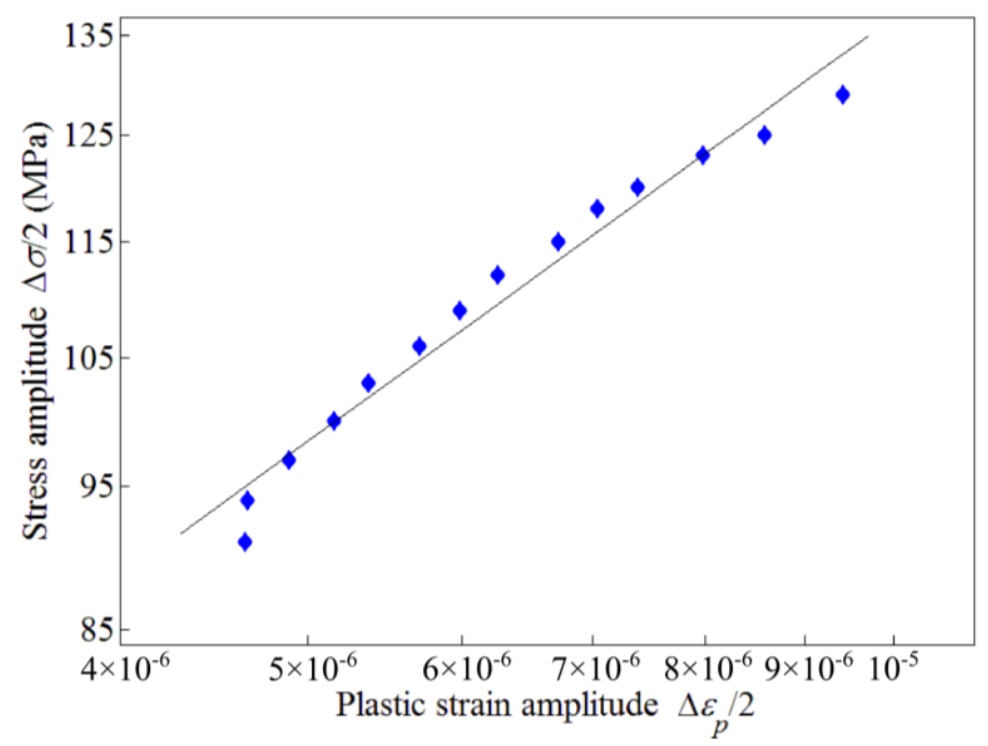

Fig. 8. The stress amplitude $\Delta \sigma / 2$ as a function of plastic strain amplitude $\Delta \varepsilon_{p} / 2$ in the stress amplitude range from $91 \mathrm{MPa}$ to $129 \mathrm{MPa}$

\subsection{The fatigue life diagram}

Regarding the aspect of the fatigue performance, the fatigue data of the fourteen constant amplitude tests applied to the pure copper specimens are reported in Table 2. The "no failure" in the table indicates that the fatigue failure did not occur until the $1 \times 10^{9}$ cycles and then the test was suspended.

It is commonly accepted that the microplasticity associated with the irreversible cyclic slip is the primary VHCF mechanism in the pure polycrystalline copper [19-22]. Hence, the plastic strain amplitude is considered as a more intrinsic fatigue indicator than the stress amplitude and is therefore preferred to be related with the fatigue life. Their relationship can be established using the classical Manson-Coffin law, formulated as below

$$
\frac{\Delta \varepsilon_{p}}{2}=\varepsilon_{f}^{\prime}\left(2 N_{f}\right)^{c}
$$

where $\varepsilon_{f}^{\prime}$ represents the fatigue ductility coefficient and $c$ the fatigue ductility exponent. 
Table 2 Fatigue data of the fourteen constant amplitude tests applied to the pure copper

\begin{tabular}{ccc}
\hline NO. of test & $\Delta \sigma / 2(\mathrm{MPa})$ & $N_{f}$ \\
\hline 1 & 110 & no failure \\
2 & 120 & no failure \\
3 & 120 & $5.19 \times 10^{7}$ \\
4 & 125 & $8.98 \times 10^{8}$ \\
5 & 130 & $1.09 \times 10^{8}$ \\
6 & 130 & $6.61 \times 10^{7}$ \\
7 & 130 & no failure \\
8 & 135 & $1.18 \times 10^{8}$ \\
9 & 135 & $5.64 \times 10^{6}$ \\
10 & 140 & $3.62 \times 10^{7}$ \\
11 & 145 & $1.37 \times 10^{7}$ \\
12 & 145 & $8.20 \times 10^{5}$ \\
13 & 150 & $2.98 \times 10^{6}$ \\
14 & 150 & $4.32 \times 10^{5}$ \\
\hline
\end{tabular}

The fatigue ductility parameters were determined as $\varepsilon_{f}^{\prime}=1.14 \times 10^{-4}$ and $c=-0.15$ by using the method of least squares applied to the fatigue data. Fig. 9 illustrates the $\Delta \varepsilon_{p} / 2-N_{f}$ data and their regression relationship established via Eq. (20) in the double-logarithm coordinate. One can note that most of the fatigue data are rather approaching to the linear regression curve within the lifespan from $4 \times 10^{5}$ to $1 \times 10^{9}$ cycles. It suggests that the Manson-Coffin law, conventionally used in the low cycle fatigue (LCF) analysis, is also applicable for the high cycle fatigue (HCF) regime and, in particular, the very high cycle fatigue regime. Hence, the fatigue life of the investigated pure copper in the VHCF regime can be predicted using the measured plastic strain amplitude in the ultrasonic fatigue test according to Eq. (20). The predicted fatigue life can be obtained by

$$
N_{f, p}=\frac{1}{2}\left(\frac{\Delta \varepsilon_{p}}{2 \varepsilon_{f}^{\prime}}\right)^{-c}
$$

where $N_{f, p}$ represents the predicted fatigue life. 


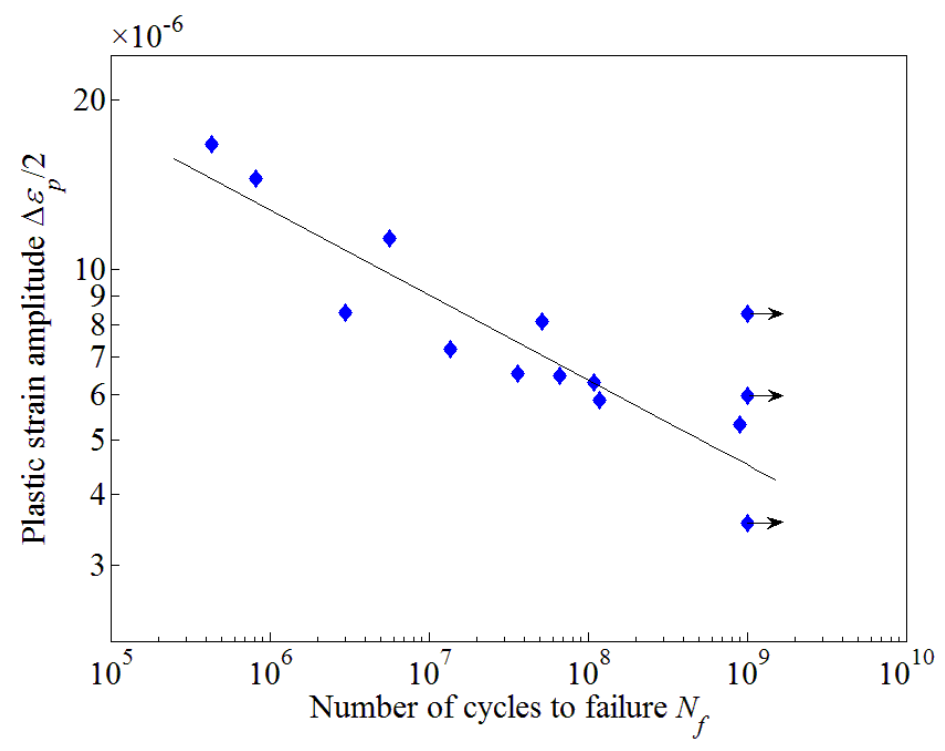

Fig. 9. Plastic strain amplitude $\Delta \varepsilon_{p} / 2$ as a function of fatigue life $N_{f}$ within the lifespan from

$$
4 \times 10^{5} \text { to } 1 \times 10^{9} \text { cycles }
$$

Fig. 9 shows that the plastic strain amplitude of the pure copper may vary from several microstrain to about ten microstrain in the VHCF regime. Here it is important to emphasize that the plastic strain is a variable with the periodic stress, and it is constituted by two components of tensile strain and compressive strain in the present case of fully reversed loading. The developed microplasticity evaluation method in this work is based on the energy balance in a load cycle to estimate the plastic strain amplitude. It is, however, not able to derive the transient plastic strain for a given moment. Despite of this, two basic facts can still be determined. First, the mean tensile (or compressive) plastic strain in a half cycle of tension (or compression) should be certainly lower than the plastic strain amplitude considering that the applied stress varies in a sinusoidal waveform. Second, the mean plastic strain in a complete cycle cannot be zero. In other words, there should exist a net plastic strain per cycle, though its absolute value could be extremely small in the VHCF regime, possibly lower than the plastic strain amplitude by several orders of magnitude. Viewed from a mesoscopic standpoint, the back-and-forth movement of the slip bands under cyclic stress is partially unrecoverable, leading to therefore permanent plastic deformation and damage accumulation. The appearance of the irreversible slip bands in the VHCF regime in pure polycrystalline copper was reported in the literature [19-22]. In particular, the experimental investigation by scanning electron 
microscopy (SEM) and atomic force microscopy (AFM) in [21] demonstrated that the persistent slip markings can still be produced after $10^{8}$ even $10^{9}$ cycles in the ultrasonic fatigue test. It is in fair agreement with the present study that evidenced the continued existence of energy dissipation of the pure copper under varied stress levels in the VHCF regime. It is commonly believed that the dissipated energy is proportional or at least positively related to the latent energy stored within the material during plastic deformation. The latent energy contributes directly to the microstructure evolution during the fatigue process, e.g., the dislocation movement and multiplication. Hence, to adopt the plastic strain amplitude derived from dissipated energy as the damage indicator is rational in a physical sense.

In the present investigation, it is also of interest to plot the fatigue life by the conventional $S-N$ curve in comparison with the Manson-Coffin type fatigue life diagram. Fig. 10 illustrates the stress amplitude $\Delta \sigma / 2$ as a function of fatigue life $N_{f}$. Their relationship is supposed to satisfy the Basquin law:

$$
\frac{\Delta \sigma}{2}=\sigma_{f}^{\prime}\left(2 N_{f}\right)^{b}
$$

with $\sigma_{f}^{\prime}=212 \mathrm{MPa}$ and $b=-0.02$, where $\sigma_{f}^{\prime}$ represents the fatigue strength coefficient and $b$ the fatigue strength exponent. The parameters are determined by the linear regression analysis based on the method of least squares.

By comparing the two fatigue life diagrams in Figs. 9 and 10, it is visible that the fatigue data show more scattered and deviated from the regression line in the $S-N$ curve. In contrast, the plastic strain amplitude-fatigue life curve in Fig. 9 demonstrates a much better fitting effect. It suggests that the plastic strain amplitude based Manson-Coffin law is more appropriate to be used to predict the fatigue life of the pure polycrystalline copper than the stress amplitude based Basquin law. We consider that this strain-controlled lifetime law may have a general applicability to the type I materials as the cyclic-slip-induced plasticity is their mutual fatigue mechanism. 


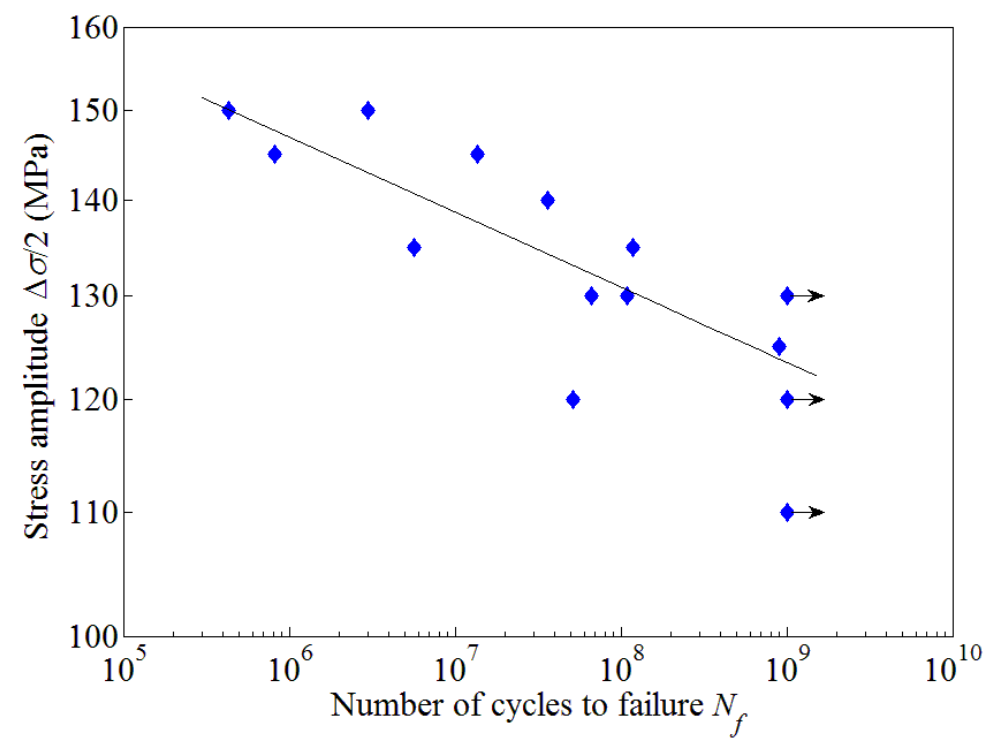

Fig. 10. Stress amplitude $\Delta \sigma / 2$ as a function of fatigue life $N_{f}$ within the lifespan from $4 \times 10^{5}$ to

$$
1 \times 10^{9} \text { cycles }
$$

\section{Conclusions}

A novel experimental method for microplasticity evaluation dedicated to the VHCF test is developed in this study. The proposed method needs first an estimation of the intrinsic dissipation from the measured temperature fields through a suitable heat diffusion model. Then an energy balance can be built between the dissipated energy and plastic work by assuming a constant heat conversion ratio. Two technical approaches suited to the two different heat development stages are proposed for the assessment of plastic strain amplitude under fatigue load. The estimated plastic strain can be in a considerably low magnitude on the level of microstrain as the heat dissipation is very sensitive to the progressive microstructure evolution pertaining to fatigue damage.

The proposed method is applied to the microplasticity evaluation of a pure polycrystalline copper in the VHCF regime. The analysis shows that the estimated plastic strain amplitude is rather small and increases smoothly with the stress amplitude under the low stress levels. The $\Delta \sigma / 2-\Delta \varepsilon_{p} / 2$ relationship for the stress amplitude below $130 \mathrm{MPa}$ can be well described using a power function. For the relatively high stress levels, the plastic strain shows a fast growth with the stress amplitude. In the concerned VHCF regime, the evaluated plastic strain amplitude is 
basically on the order of magnitude of $10^{-6}$. Since the microplasticity associated with irreversible cyclic slip is considered as the primary mechanism of the VHCF in fcc materials, it is therefore proposed to relate the estimated plastic strain amplitudes with the fatigue lives of the material through the Manson-Coffin law. The result demonstrates a satisfactory linear double-logarithmic correlation between the two elements. In particular, it outperforms the presentation of fatigue life by using the $S$ - $N$ curve. Hence, it suggests that the MansonCoffin law, usually used in the LCF analysis, can also be applied to the VHCF regime.

The plastic deformation and associated heat dissipation is a common feature of the fatigue damage in metallic materials. Thus the proposed calorimetric method is versatile for the metal fatigue investigation. It demonstrates particular values in the microplasticity assessment in the VHCF regime as the heat dissipation is sensitive enough to detect the tiny fatigue damage even under very low stress levels. The studied material in this work is a pure polycrystalline copper as the type I fcc material. It is thus also attractive to extend the present study to the type II materials, e.g., high strength steels, which are generally believed being possessed of an alternative fatigue mechanism than the type I materials. Moreover, the proposed method still needs a rigorous experimental validation regarding the measurement precision of the microplastic strain. We attempt to employ the micro DIC methodology [48] developed recently to perform such a validation on the microstructure scale. By this method, the plastic strain can be solved on the scale of the slip band. Then it serves not only for the strain quantity verification, and it also provides the possibility to study the correlations between the plastic strain, microstructure evolution, and fatigue damage in a concurrent way. Such an investigation is in progress.

\section{Acknowledgements}

This work is supported by the Major Program of National Science Foundation of China (Grant No. 51490662), the National Science Foundation for Excellent Young Scholars of China (Grant No. 51222502), the National Science Foundation of China (Grant No. 11402297), 
and the Fund for Distinguished Young Scientists of Hunan Province of China (Grant No. 14JJ1016), and the National Excellent Doctoral Dissertation Special Fund of China (Grant No.201235).

\section{References}

[1] Suresh S. Fatigue of materials. Cambridge: Cambridge university press, 1998.

[2] Murakami Y. Metal fatigue: effects of small defects and nonmetallic inclusions: effects of small defects and nonmetallic inclusions. Oxford: Elsevier Science, 2002.

[3] Takahashi Y, Shikama T, Yoshihara S, et al. Study on dominant mechanism of highcycle fatigue life in 6061-T6 aluminum alloy through microanalyses of microstructurally small cracks. Acta Materialia, 2012, 60(6): 2554-2567.

[4] Jiang C, Liu Z C, Wang X G, et al. A structural stress-based critical plane method for multiaxial fatigue life estimation in welded joints. Fatigue \& Fracture of Engineering Materials \& Structures, 2016, 39: 372-383.

[5] Bathias C, Paris P C. Gigacycle fatigue in mechanical practice. New York: Marcel Dekker, 2005.

[6] Stöcker C, Zimmermann M, Christ H J. Effect of precipitation condition, prestrain and temperature on the fatigue behaviour of wrought nickel-based superalloys in the VHCF range. Acta Materialia, 2011, 59(13): 5288-5304.

[7] Qian G, Zhou C, Hong Y. Experimental and theoretical investigation of environmental media on very-high-cycle fatigue behavior for a structural steel. Acta Materialia, 2011, 59(4): 1321-1327.

[8] Mayer H. Recent developments in ultrasonic fatigue. Fatigue \& Fracture of Engineering Materials \& Structures, 2016, 39(1): 3-29.

[9] Naito T, Ueda H, Kikuchi M. Fatigue behavior of carburized steel with internal oxides and nonmartensitic microstructure near the surface. Metallurgical Transactions A, 1984, 15(7): 1431-1436.

[10] Murakami Y, Nomoto T, Ueda T. Factors influencing the mechanism of superlong fatigue failure in steels. Fatigue \& Fracture of Engineering Materials \& Structures, 1999, 22(7): 581-590.

[11] Sakai T, Sato Y, Oguma N. Characteristic S-N properties of high-carbon-chromiumbearing steel under axial loading in long-life fatigue. Fatigue \& Fracture of Engineering Materials \& Structures, 2002, 25(8-9): 765-773. 
[12] Wang Q Y, Bathias C, Kawagoishi N, et al. Effect of inclusion on subsurface crack initiation and gigacycle fatigue strength. International Journal of Fatigue, 2002, 24(12): 1269-1274.

[13] Yang Z G, Li S X, Zhang J M, et al. The fatigue behaviors of zero-inclusion and commercial 42CrMo steels in the super-long fatigue life regime. Acta Materialia, 2004, 52(18): 5235-5241.

[14] Huang Z, Wagner D, Bathias C, et al. Subsurface crack initiation and propagation mechanisms in gigacycle fatigue. Acta Materialia, 2010, 58(18): 6046-6054.

[15] Hong Y, Lei Z, Sun C, et al. Propensities of crack interior initiation and early growth for very-high-cycle fatigue of high strength steels. International Journal of Fatigue, 2014, 58: 144-151.

[16] Mughrabi H. On the life-controlling microstructural fatigue mechanisms in ductile metals and alloys in the gigacycle regime. Fatigue \& Fracture of Engineering Materials \& Structures, 1999, 22(7): 633.

[17] Mughrabi H. Specific features and mechanisms of fatigue in the ultrahigh-cycle regime. International Journal of Fatigue, 2006, 28(11): 1501-1508.

[18] Sakai T, Lian B, Takeda M, et al. Statistical duplex S-N characteristics of high carbon chromium bearing steel in rotating bending in very high cycle regime. International Journal of Fatigue, 2010, 32(3): 497-504.

[19] Stanzl-Tschegg S, Mughrabi H, Schoenbauer B. Life time and cyclic slip of copper in the VHCF regime. International Journal of Fatigue, 2007, 29(9): 2050-2059.

[20] Weidner A, Amberger D, Pyczak F, et al. Fatigue damage in copper polycrystals subjected to ultrahigh-cycle fatigue below the PSB threshold. International Journal of Fatigue, 2010, 32(6): 872-878.

[21] Phung N L, Favier V, Ranc N, et al. Very high cycle fatigue of copper: Evolution, morphology and locations of surface slip markings. International Journal of Fatigue, 2014, 63: 68-77.

[22] Phung N L, Favier V, Ranc N. Evaluating Schmid criterion for predicting preferential locations of persistent slip markings obtained after very high cycle fatigue for polycrystalline pure copper. International Journal of Fatigue, 2015, 77: 115-127.

[23] Sutton M A, Orteu J J, Schreier H. Image correlation for shape, motion and deformation measurements: Basic Concepts, Theory and Applications. New York: Springer, 2009.

[24] Ni J, Zhang X. Determination of stress intensity factor in ultrasonic fatigue loading by means of dynamic modal analysis and three-dimensional finite element calculation. Engineering Fracture Mechanics, 1995, 52(6): 1079-1086. 
[25] Tsutsumi N, Murakami Y, Doquet V. Effect of test frequency on fatigue strength of low carbon steel. Fatigue \& Fracture of Engineering Materials \& Structures, 2009, 32(6): 473-483.

[26] Kumar A, Torbet C J, Pollock T M, et al. In situ characterization of fatigue damage evolution in a cast $\mathrm{Al}$ alloy via nonlinear ultrasonic measurements. Acta Materialia, 2010, 58(6): 2143-2154.

[27] Kumar A, Adharapurapu R R, Jones J W, et al. In situ damage assessment in a cast magnesium alloy during very high cycle fatigue. Scripta Materialia, 2011, 64(1): 65-68.

[28] Ranc N, Wagner D, Paris P C. Study of thermal effects associated with crack propagation during very high cycle fatigue tests. Acta Materialia, 2008, 56(15): 4012-4021.

[29] Krewerth D, Lippmann T, Weidner A, et al. Application of full-surface view in situ thermography measurements during ultrasonic fatigue of cast steel G42CrMo4. International Journal of Fatigue, 2015, 80: 459-467.

[30] Crupi V, Epasto G, Guglielmino E, et al. Analysis of temperature and fracture surface of AISI4140 steel in very high cycle fatigue regime. Theoretical and Applied Fracture Mechanics, 2015, 80: 22-30.

[31] Huang Z Y, Wang Q Y, Wagner D, et al. A very high cycle fatigue thermal dissipation investigation for titanium alloy TC4. Materials Science and Engineering: A, 2014, 600: 153-158.

[32] Blanche A, Chrysochoos A, Ranc N, et al. Dissipation assessments during dynamic very high cycle fatigue tests. Experimental Mechanics, 2015, 55(4): 699-709.

[33] Charkaluk E, Constantinescu A. Dissipative aspects in high cycle fatigue. Mechanics of Materials, 2009, 41(5): 483-494.

[34] Connesson N, Maquin F, Pierron F. Dissipated energy measurements as a marker of microstructural evolution: 316L and DP600. Acta Materialia, 2011, 59(10): 4100-4115.

[35] Mareau C, Favier V, Weber B, et al. Micromechanical modeling of the interactions between the microstructure and the dissipative deformation mechanisms in steels under cyclic loading. International Journal of Plasticity, 2012, 32: 106-120.

[36] Chrysochoos A, Louche H. An infrared image processing to analyse the calorific effects accompanying strain localisation. International Journal of Engineering Science, 2000, 38(16): 1759-1788.

[37] Boulanger T, Chrysochoos A, Mabru C, et al. Calorimetric analysis of dissipative and thermoelastic effects associated with the fatigue behavior of steels. International Journal of Fatigue, 2004, 26(3): 221-229.

[38] Mareau C, Favier V, Weber B, et al. Influence of the free surface and the mean stress on the heat dissipation in steels under cyclic loading. International Journal of Fatigue, 2009, 31(8): 1407-1412. 
[39] Doudard C, Calloch S, Hild F, et al. Identification of heat source fields from infrared thermography: Determination of 'self-heating' in a dual-phase steel by using a dog bone sample. Mechanics of Materials, 2010, 42(1): 55-62.

[40] Wang X G, Witz J F, El Bartali A, et al. Quantitative infrared thermography applied to subgrain scale and the effect of out-of-plane deformation. Infrared Physics and Technology, 2015, 71: 432-438.

[41] Greene R J, Patterson E A, Rowlands R E. Thermoelastic stress analysis. Springer Handbook of Experimental Solid Mechanics. New York: Springer, 2008.

[42] Amiri M, Khonsari M M. Rapid determination of fatigue failure based on temperature evolution: Fully reversed bending load. International Journal of Fatigue, 2010, 32(2): 382-389.

[43] Poncelet M, Doudard C, Calloch S, et al. Probabilistic multiscale models and measurements of self-heating under multiaxial high cycle fatigue. Journal of the Mechanics and Physics of Solids, 2010, 58(4): 578-593.

[44] Wang X G, Crupi V, Jiang C, et al. Quantitative Thermographic Methodology for fatigue life assessment in a multiscale energy dissipation framework. International Journal of Fatigue, 2015, 81: 249-256.

[45] Farren, W S, Taylor, G I. The heat developed during plastic extension of metals. Proceedings of The Royal Society of London A, 1925, 107: 422-451.

[46] Papakyriacou M, Mayer H, Plenk H, et al. Cyclic plastic deformation of tantalum and niobium at very high numbers of cycles. Materials Science and Engineering: A, 2002, 325(1): 520-524.

[47] Zettl B, Mayer H, Ede C, et al. Very high cycle fatigue of normalized carbon steels. International Journal of Fatigue, 2006, 28(11): 1583-1589.

[48] Wang X G, Witz J F, El Bartali A, et al. A dedicated DIC methodology for characterizing plastic deformation in single crystals. Experimental Mechanics, 2016, DOI: 10.1007/s11340-016-0159-9 